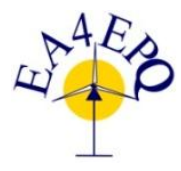

International Conference on Renewable Energies and Power Quality (ICREPQ'17) Malaga (Spain), $4^{\text {th }}$ to $6^{\text {th }}$ April, 2017

Renewable Energy and Pourer Qualiily. Fournal (RE\&PQJ)

ISSN 2172-038 X, No.15 April 2017

\title{
Income generation of rural community by using solar distillation system
}

\author{
A. Afzal ${ }^{1 *}$, J. Alvarado $^{2}$, A. Munir ${ }^{1}$ and A. Ghafoor ${ }^{1}$ \\ ${ }^{1}$ Faculty of Agricultural Engineering \& Technology, University of Agriculture, Faisalabad-Pakistan \\ Phone/Fax number: +0092 332 6975287, e-mail: arslan2175@ hotmail.com \\ ${ }^{2}$ Department of Engineering Technology \& Industrial Distribution, Texas A \& M University-USA
}

\begin{abstract}
Processing of different herbs by distillation technique was one of the agro-based industries which lie in medium temperature range $\left(60-280^{\circ} \mathrm{C}\right)$. This study has been carried out for essential oils extraction using solar distillation system as well as to perform the quality analysis of eucalyptus leaves (comaldulensis) essential oils using GCMS analysis for income generation of rural community. The solar distillation system consists of a primary reflector (10 $\mathrm{m}^{2}$ Scheffler concentrator), a secondary reflector, distillation still, condenser and Florentine flasks. Results have shown that the essential oil from $10 \mathrm{~kg}$ fresh eucalyptus leaves (comaldulensis) for different experiments were extracted to be 29.7, 30, 28.2, 29.9 and $30.2 \mathrm{ml}$. GCMS analysis shows that eucalyptol $\left(\mathrm{C}_{10} \mathrm{H}_{16} \mathrm{O}\right)$ was identified as the most dominant compound of eucalyptus leaves (comaldulensis) essential oil $(50.91 \%)$. This is the great opportunity of small scale farmer to on-farm solar industry for income generation of rural community.

Keywords: Scheffler concentrator, Solar distillation system, Essential oil, GC-MS analysis, Income generation.
\end{abstract}

\section{Introduction}

From last various years energy crisis is the major problem of developing countries. No attention was given in the past decade to increase the sources of power generation to meet the needs of rapidly growing population. An energy crisis is huge loss in the supply of energy resources to the economy of a country. Accessibility of energy in any country has a strong correlation with its economic and social solidity. Now time has come when we should introduce renewable energy resources to overcome the energy crises and replace the fossil fuel utilization for power generation because of hastily increasing prices of fossil fuel.

Solar energy is clean, free and the most abundant, source of renewable energy. The sun has been used as the source of energy in different ways for many centuries. A number of studies that have been conducted on heat demand for several industries show that the application of solar energy is favorable in different industrial sector. Much industrial process that required medium temperature range are Pasteurization, extraction, sterilization, drying, hydrolyzing, distillation, evaporation, washing and polymerization. The temperature ranges for all above processes lie between $60-280^{\circ} \mathrm{C}$ [1]. For cooking and steam generation purposes solar energy is utilized by human beings now a days but the solar energy utilization for the extracting of the essential oil from the medicinal and aromatic plants is an innovative application of solar energy.

Distillations is the process of extracting of the clean and refine oil from the plant material by evaporating the volatile essence of these plant materials and having many advantages over other oil extracting methods [2]. Steam or water distilled volatile products of the plant materials are called essential oil. An essential oil is a complicated mixture of chemical compounds which are responsible for its definite characteristics. These oils are used in medicinal, food, pharmaceutical and perfume industries. Essential oils are highly concentrated, volatile essence of plant. Scientist agrees that essential oil may perform more than one function in living plant. In some cases, they seem to be a part of plant's immune system. In other cases, they may simply be end product of metabolism. Essential oils contain hundreds of organic constituent, including hormones, vitamins and other natural element that work on many level.

Different methods are used to extract the essential oil from the plant materials. These methods are as water or hydro distillation, steam distillation, water cum steam distillation and steam distillation. Among all above processes steam distillation is the most favorable process. In steam distillation steam is passing through the plant materials and this steam evaporates the oil contents from the materials and the mixture of oil and water after condensation is called condensed distillate. Florentine flask is used to separate the oil and water from condensed 
distillate. Oil separation is based on the property of the oils that they are insoluble in water. In Florentine flask oil and water are appeared in two distinct layers mostly oils come at the top of water because they are lighter in weight than water.

Many countries like China, India, South Africa, Portugal, Brazil and Tasmania are engaged in the production of essential oil of eucalyptus for commercial use. In 1992 it was estimated that 4000 tons of Eucalyptus was produced in the world and about $60-70 \%$ of it was used in medicinal industry. Eucalyptus oil is used in different disease as cold, chest pain, influenza, chest problems and skin rashes are treated by the use of essential oil of different species of eucalyptus. To oppose inflammation its oil vapors are inhaled.

For quality analysis gas chromatography and gas chromatographic mass spectrometry analysis of solar distilled essential oil has been conducted. Gas chromatography is a technique used to analyze and separate the vaporized compounds in analytical chemistry. To test the purity of substance and separation of different compounds from a complex mixture of chemicals is the main application of gas chromatography. The preparation of the pure compounds from the complex mixture of chemical for the preparative chromatography is done by gas chromatography [3]. Gas chromatography- mass spectrometry is the advance form of the gas chromatographic analysis in which Gas chromatograph couples with mass spectrometer. Main advantage of this coupling is that more detailed analysis of sample is done by the spectral interpretation.

\section{MATERIALS AND METHODS}

This study was conducted specially to optimize the solar distillation system for the quality enhancement of medicinal plants and to make sure the quality of solar distilled essential of medicinal plants.

\subsection{Experimental setup of solar distillation System}

A distillation system normally comprises of four main parts: furnace, distillation still, condenser and oil separator as Florentine flask. But this system was comprised of primary reflector, secondary reflector, distillation still, condenser, and Florentine flask. There are three types of distillation in practice as water distillation, steam distillation and water and steam distillation. All these can be performed by using solar distillation system. In this study water and steam distillation has been used. A complete solar distillation system is shown in Figure. 1 description of all above parts of solar distillation is as under.

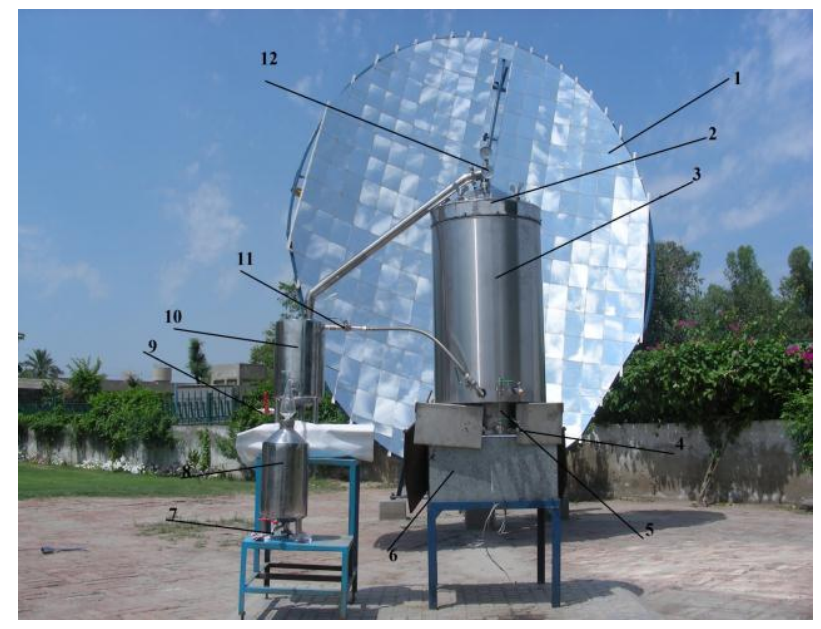

Figure: 1 A complete solar distillation system

(1-Primary reflector, 2-Top cover of distillation still, 3Distillation still, 4-outlet for water, 5-water level indicator,6-Secondry reflector, 7- outlet for hydrosol from Florentine flask, 8-Florentine flask, 9- water inlet toward Condenser, 10- Condenser, 11- Hot water outlet from condenser and 12-Pressure gauges)

Fresh leaves of eucalyptus (comaldulensis) were collected from the eucalyptus tree infant side of horticultural laboratory tree in the University of Agriculture Faisalabad. Experiments of solar distillation were carried out by solar distillation system which has been installed at Rosa Lab, Institute of Horticultural Sciences in University of Agriculture Faisalabad. Experiment start with the opening of the distillation still cover before to loading it with the $10 \mathrm{~kg}$ leaves of eucalyptus. Still is charged with leaves of eucalyptus, after checking the cover seal cover of distillation still was placed. Under the available size of the distillation still, the minimum water level $120 \mathrm{~mm}$ is maintained in the distillation prototype. This water level exposed to the solar radiations corresponds to the surface area of the still [4-5]. The system is equipped with pyranometer and thermocouples in order to evaluate and control the solar distillation system continuously during the experiments. Solar radiation intensity was recorded by the pyranometer (SP Lite: response time < $1 \mathrm{~s}$ ). The pyranometer with a black pipe $(0.020 \mathrm{~m}$ long $)$ was fixed at the major axis of the primary reflector with the help of adjustable lever for the recording of beam radiation only. For the record of temperature of steam, water and focal point, thermocouples connections were provided. All thermocouples and pyranometer connections were attached to a computer through data logger. Before starting the experiment the setting of focus was done by opening the bolts of telescopic clamps to make the reflector seasonal tracking axis to free. Due to presence of clutch plate the rotation along daily tracking axis is always flexible. Telescopic clamps also helps in to set the focus accurately by holding it either from top side or bottom side. By visualizing the illuminated beam of solar radiation the optimum focus is set. If the focus is not an accurate 
position on the secondary reflector door or a little bit higher than the designed focus point, then the top side of the reflector is tightened by fixing the downward side and vice versa. The position of pyranometer is adjusted to record the maximum beam radiations. The data is recorded after 10 min intervals for the temperatures and beam radiations with the help of thermocouples and pyranometer respectively.

During the process of leaves of eucalyptus all the running distillation parameters were observed. When the steam generation started the flow rate of water condenser was established. When the process is over, the reflector is rotated out of the focus to stop the distillation process; the spent charge material is removed manually using a hay hook. The still is drained out and washed. If there much residual leaves of eucalyptus material remaining in the still, it may be necessary to lift out the charge tray and hose the strainer clear of the material. The still is filled with water again to set the level. The distillation cycle is now complete and the still is ready for the next distillation cycle.

\subsection{Heat energy $\left(E_{p}\right)$ calculation}

The complete heat energy $\left(\mathrm{E}_{\mathrm{p}}\right)$ during distillation procedure of leaves of eucalyptus in $\mathrm{kWh}$ can be determined by the Eq. (2).

$$
E_{p}=\left[\left\{\left(m_{w}+M_{w} m_{h}\right) c_{w}+m_{h}\left(1-M_{w}\right) c_{f}\right\} \Delta T+x_{s} h_{f g}\right] / 3600(1)
$$

Where

$\mathrm{M}_{\mathrm{w}}$ is moisture content of leaves of eucalyptus, $\mathrm{m}_{\mathrm{w}}$ is 15 litter of water was used to fill the bottom area of the distillation still which exposed to solar radiations, $\mathrm{m}_{\mathrm{h}} 10$ $\mathrm{kg}$ of leaves of eucalyptus was used in one batch, $\mathrm{h}_{\mathrm{fg}}$ is latent heat of vaporization at atmospheric pressure is 2260 $\mathrm{kJ} \mathrm{kg}^{-1}, \mathrm{c}_{\mathrm{w}}$ is specific heat of water at constant pressure is $4.186, c_{f}$ is specific heat of fiber is $1.26, \Delta \mathrm{T}$ is change in temperature, $\mathrm{x}$ is quality of steam or steam dryness fraction and $\mathrm{m}_{\mathrm{s}}$ is the mass of steam.

\subsection{GCMS analysis}

Gas chromatography analysis of solar and conventional distilled oils of leaves of eucalyptus had been conducted by a Shimadzu 17-A gas chromatograph equipped with flame ionization detector (FID). Helium gas having flow rate of $1.0 \mathrm{ml} / \mathrm{min}$ was used as a carrier gas. The temperature has been initially maintained at $45^{\circ} \mathrm{C}$ for 6 min and subsequently programmed to reach $250{ }^{\circ} \mathrm{C}$ for 10 min@ @ $3{ }^{\circ} \mathrm{C}$ per min. Both the injection and detection temperature were adjusted as $250{ }^{\circ} \mathrm{C}$. NIST mass spectral library ( $\mathrm{v} 2.0 \mathrm{a}$ 2002) has been used to identify the compounds by comparing their mass spectral with the mass spectral of base data.

\subsection{Economic evaluation}

Cost analysis was done to determine whether the solar system is as cost effective as conventional system for extraction of essential oil. The purpose of the economic evaluation was to determine if it is a sound investment to install solar distillation system and it involves comparing the expected cost of total system against the total expected benefits

\subsection{Statistical analysis}

Several experiments have been conducted and the regression analysis was performed to determine appropriate model of the process curves. The analyses have been carried out to compare different parameters at $5 \%$ level of significance.

\section{Results and discussion}

The extraction of essential oil from leaves of eucalyptus has been carried out using solar distillation system. Steam distillation method was used to extract the essential oil from the leaves of eucalyptus. The results obtained from this distillation have been presented as follows:

\subsection{Field experiments using solar distillery}

$10 \mathrm{~kg}$ of fresh eucalyptus leaves (comaldulensis) was used for distillation purpose. The yields of essential oils for five different experiments have been measured to be $29.7,30,28.2,29.9$ and $30.2 \mathrm{ml}$ with average quantity of essential oil as $0.296 \%$. The heat energy required for $10 \mathrm{~kg}$ fresh eucalyptus leaves (comaldulensis) has also been calculated. The essential oil yields and heat energy required for essential oil extraction is shown in Table 1. The distillation curves for percent of total oil extracted against heat energy $(\mathrm{kWh})$ have been shown in Figure 2.

Table.1: Essential oil yield during different experiments

\begin{tabular}{|c|c|c|c|c|c|}
\hline $\begin{array}{l}\text { Sr } \\
\dot{\text { N }} \\
\text { o. }\end{array}$ & $\begin{array}{l}\text { Experi } \\
\text { ment } \\
\text { No. }\end{array}$ & $\begin{array}{l}\text { Weight of } \\
\text { Eucalyptus } \\
\text { (Camaldule } \\
\text { nsis) (kg) }\end{array}$ & $\begin{array}{c}\text { Avera } \\
\text { ge } \\
\text { Moist } \\
\text { ure } \\
\text { conten } \\
\text { t } \\
\text { (wb) } \\
\%\end{array}$ & $\begin{array}{c}\text { Avera } \\
\text { ge } \\
\text { Heat } \\
\text { energ } \\
\text { y } \\
\text { requi } \\
\text { red } \\
(\mathrm{kWh} \\
\text { ) }\end{array}$ & $\begin{array}{c}\text { Avera } \\
\text { ge } \\
\text { Essent } \\
\text { ial oil } \\
\text { extrac } \\
\text { ted } \\
\text { (ml) }\end{array}$ \\
\hline 1 & $\operatorname{Exp} 1$ & 10 & 64 & 2.998 & 29.7 \\
\hline 2 & $\operatorname{Exp} 2$ & 10 & 65 & 2.745 & 30 \\
\hline 3 & $\operatorname{Exp} 3$ & 10 & 66 & 2.888 & 28.2 \\
\hline 4 & $\operatorname{Exp} 4$ & 10 & 63 & 2.816 & 29.9 \\
\hline \multirow[t]{2}{*}{5} & $\operatorname{Exp} 5$ & 10 & 64 & 2.418 & 30.2 \\
\hline & Mean & 10 & 64.4 & 2.773 & 29.6 \\
\hline
\end{tabular}




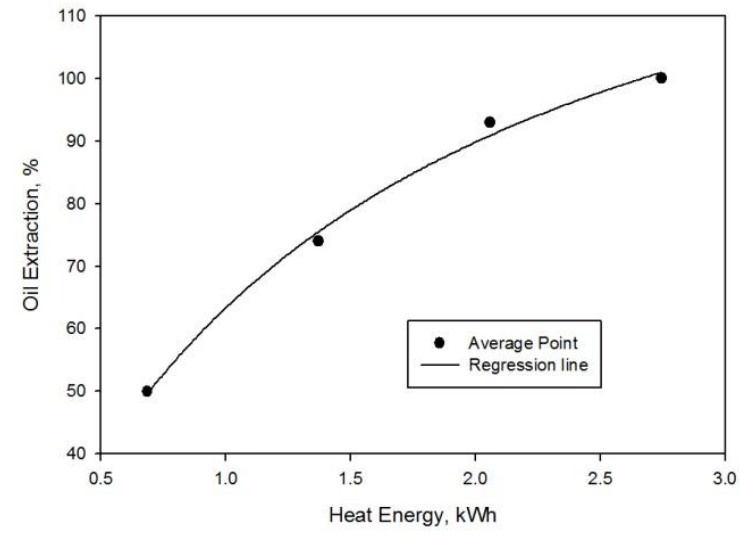

Figure.2 Essential oil extracted against heat energy required

Regression analysis has been performed for the best fitted model for the percentage of oil extract against heat energy required for the distillation process. The best fitted regression model for all plant materials was found to be the sigmoid/logistic as shown in Eq. (2).

$$
=\frac{k}{1+\left(\frac{z}{z_{o}}\right)^{i}}
$$

Where $y$ and $z$ are the variables of the regression model and $k, l, z_{o}$ are the coefficients of regression model. The reliability of the developed model was evaluated by comparing the experimental and predicted curves. The model fitted the results well as indicated by high values of coefficient of determination $\left(\mathrm{R}^{2}=0.9974\right)$. The results show higher oil extraction rates at the start of the distillation process and very lower oil extraction rate at the end of the distillation experiment.

\subsection{GC-MS analysis of eucalyptus leaves (comaldulensis) essential oil}

The Gas Chromatography-Mass Spectrometry (GC-MS) analyses were carried out for the quality aspects of eucalyptus leaves (comaldulensis) essential oil components extracted using solar distillation system. Five samples $(29.7,30.0,28.9,29.9,30.2 \mathrm{ml})$ of eucalyptus leaves (comaldulensis) essential oils have been mixed to get mono sample for GC-MS analysis. The chemical components along with their percentages were identified in eucalyptus leaves (comaldulensis) essential oils during GCMS analyses Eucalyptol $\left(\mathrm{C}_{10} \mathrm{H}_{16} \mathrm{O}\right)$ was identified as the most dominant compound of eucalyptus leaves (comaldulensis) essential oil $(50.9 \%)$. It is worth mentioning that the solar distilled oil contains high percentage of the most vital compound of "Eucalyptol" which can be effectively used for making medicine flavoring, fragrance etc. In solar distilled eucalyptus leaves (comaldulensis) essential oil, total 17 compounds were identified. $\gamma$-Terpinene $\left(\mathrm{C}_{10} \mathrm{H}_{16}\right)$ has low concentration $(12.145 \%)$. It is used in cosmetics and food industries. Other compound with low concentration is $\gamma$-Elemene $\left(\mathrm{C}_{15} \mathrm{H}_{24}\right)$ is $(9.518 \%)$, IR- $\alpha$-Pinene $\left(\mathrm{C}_{10} \mathrm{H}_{16}\right)$ is $(7.076 \%)$, Aromadendrene $\left(\mathrm{C}_{15} \mathrm{H}_{24}\right)$ is $(5.459 \%)$, Spathulenol $\left(\mathrm{C}_{15} \mathrm{H}_{24} \mathrm{O}\right)$ is $(3.376 \%), 4,6,6$-Trimethyl-2-(3-methylbuta- 1,3-dienyl)-3-oxatricyclo[5.1.0.0 (2,4)] octane $\left(\mathrm{C}_{15} \mathrm{H}_{22} \mathrm{O}\right)$ is (2.097\%), Ledene oxide-(II) $\left(\mathrm{C}_{15} \mathrm{H}_{24} \mathrm{O}\right)$ is $(1.969 \%)$, $\beta$ vatirenene $\left(\mathrm{C}_{15} \mathrm{H}_{22}\right)$ is $(1.211 \%)$, Terpiolene $\left(\mathrm{C}_{10} \mathrm{H}_{16}\right)$ is $(1.19 \%)$, Terpinen-4-ol $\left(\mathrm{C}_{10} \mathrm{H}_{18} \mathrm{O}\right)$ is $(0.983 \%)$, 2-thujene $\left(\mathrm{C}_{10} \mathrm{H}_{16}\right)$ is $(0.934 \%)$, $\gamma$-Gurjunene $\left(\mathrm{C}_{15} \mathrm{H}_{24}\right)$ is $(0.877 \%)$, 4,6,6-Trimethyl-2-(3-methylbuta-1,3-dienyl)-3oxatricyclo[5.1.0.0 (2,4)]octane $\left(\mathrm{C}_{15} \mathrm{H}_{22} \mathrm{O}\right)$ is $(0.763 \%), \beta$ Myrcene $\left(\mathrm{C}_{10} \mathrm{H}_{16}\right)$ is $(0.535 \%)$, Elemene $\left(\mathrm{C}_{15} \mathrm{H}_{24}\right)$ is $(0.533$ $\%)$ and $\alpha$-Terpinene $\left(\mathrm{C}_{10} \mathrm{H}_{16}\right)$ is $(0.433 \%)$.

\subsection{Break-even analysis}

The break-even point (BEP) is the point at which cost or expenses and revenue are equal: there is no net loss or gain, and one has "broken even". A profit or a loss has not been made, although opportunity costs have been "paid", and capital has received the risk-adjusted, expected return. In short, all costs that need to be paid are paid but the profit is equal to 0 .

$$
\begin{aligned}
\mathrm{TR} & =\mathrm{TC} \\
\mathrm{P} \times \mathrm{X} & =\mathrm{TFC}+\mathrm{V} \times \mathrm{X} \\
\mathrm{X} & =\frac{\mathrm{TFC}}{\mathrm{P}-\mathrm{V}}
\end{aligned}
$$

Where,

$$
\begin{aligned}
\mathrm{TR} & =\text { Total Revenue } \\
\mathrm{P} & =\text { Price of per } \mathrm{hr} \\
\mathrm{TFC} & =\text { Total fixed costs } \\
\mathrm{X} & =\text { Operating time per } \mathrm{hr} \\
\mathrm{V} & =\text { Variable cost } \\
\mathrm{TC} & =\text { Total Costs }
\end{aligned}
$$

In this study eucalyptus leaves (comaldulensis) was used for the extraction of essential oils, the average yield of fresh eucalyptus leaves (comaldulensis) oil for one batch was $29.6 \mathrm{ml}$ and time required for the completion of extraction was about $4 \mathrm{~h}$. In one day two batches of experiment could run easily. Therefore total oil yield in a day $(8 \mathrm{~h})$ was $59.2 \mathrm{ml}$ and price of $10 \mathrm{ml}$ eucalyptus leaves (comaldulensis) essential oil was 4.50 \$ (Amazon.com:Sweetorange100\%pure)

$10 \mathrm{ml}$ of eucalyptus essential oil

$59.2 \mathrm{ml}$ of eucalyptus essential oil $=26.64 \$$

As $59.2 \mathrm{ml}$ oil could be attain from $8 \mathrm{hr}$ working of solar distillation system and price of essential oil was 26.64. Therefore earning from $1 \mathrm{hr}$ would be 3.33 US \$.

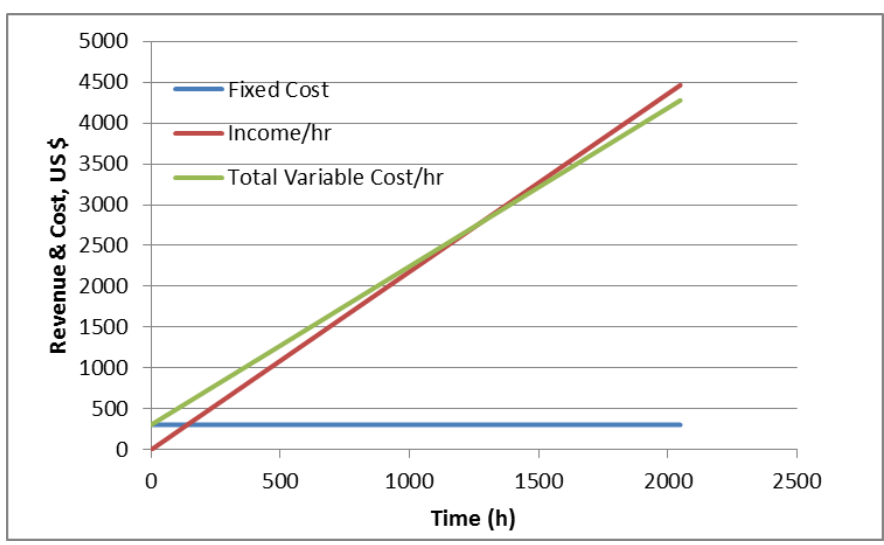

Figure.3 Break even analysis 


$$
\begin{aligned}
& X=\frac{305}{3.33-3.12} \\
& X=1452.38 \mathrm{~h} .
\end{aligned}
$$

In its simplest form, the break-even analysis is a graphical representation of costs at various levels of activity shown on the same chart as the variation of income (or sales, revenue) with the same variation in activity. The point at which neither profit nor loss is made is known as the "break-even point" and is represented on the chart below by the intersection of the two lines. The value of break-even point show that payback period of solar distillation system is $1452.38 \mathrm{~h}$ which is equal to 0.490 year. After completion of payback period system will run free of cost.

\section{Conclusion}

Results show that the essential oils extracted from $10 \mathrm{~kg}$ fresh eucalyptus leaves (comaldulensis) and heat energy required during different experiments was measured to be 29.7, 30.0,28.9, 29.9, $30.2 \mathrm{ml}$ ) and 2.998, $2.745,2.888,2.816$ and $2.418 \mathrm{kWh}$ respectively. The GCMS analysis shows that Eucalyptol $\left(\mathrm{C}_{10} \mathrm{H}_{16} \mathrm{O}\right)$ was identified as the most dominant compound of eucalyptus leaves (comaldulensis) essential oil (50.9\%), which can effectively use for making medicine flavoring, fragrance etc. In solar distilled eucalyptus leaves (comaldulensis) essential oil; total 17 compounds were identified. This is the great opportunity of small scale farmer to on-farm solar industry for income generation of rural community. The promotion of on-farm processing and value addition of agriculture produces will enhance income of rural community thus reducing rural to urban migration and eliminating the role of middle man.

\section{Acknowledgement}

The authors gratefully acknowledge German Academic Exchange serves (DAAD), International center of development and decent work (ICDD) and Higher Education Commission (HEC) of Pakistan for funding the present research work. Also, the authors are grateful for the support and guidance provided by Prof. Oliver Hensel.

\section{References}

[1] S. Kalogirou, Potential of solar industrial process heat applications. Journal of Applied Energy, 76 (2003) 337-361.

[2] B. Malle, H. Schmickl, Atherische Ole selbst herstellen, Verlag Die Werkstatt GmbH Lotzestrabe 24 a, D37083 Gottingen, (2005) 23-27.

[3] R. Francoise, Aromatherapy 101: the foundation of Aromatherapy (2003). Available on http://www.aromalchemy.com

[4] K. Durbeck, The distillation of essential oils, manufacturing and plant construction handbook, Protrade:Department Foodstuffs and agricultural products, Deutsche Geselschaft fur Technische
Zuzammenarbeit (GTZ) GmbH. P.O box 5180 D65726 Eschborn, Federal republic of Germany, (1997)

[5] E.F.K. Denny, Field distillation for Herbaceous Oils, second Edition, Denny, McKenzie associates, Lilydate, Tasmania 7268, Australia, (1991). 